\title{
PENGEMBANGAN KONFIGURASI HOTSPOT DAN VOUCHER LOGIN MENGGUNAKAN MIKROTIK RB952Ui DENGAN WEB TOP UP PADA NORALONA COFFEE ROASTERY
}

\author{
Ridho Taufiq Subagio ${ }^{1)}$, Wanda Ilham ${ }^{2)}$, Indra Romadon ${ }^{3)}$ \\ ${ }^{1}$ Fakultas Teknologi Informasi, Universitas Catur Insan Cendekia \\ email: ridho.taufiq@gmail.com \\ ${ }^{2}$ Fakultas Teknologi Informasi, Universitas Catur Insan Cendekia \\ email: wandailham@cic.ac.id \\ ${ }^{2}$ Fakultas Teknologi Informasi, Universitas Catur Insan Cendekia \\ email: indra.romadhon76@hotmail.com
}

\begin{abstract}
The current internet access needs are very high, both to find the latest information, articles and seek entertainment. There are several places that provide internet access, one of which is a coffee shop. Many coffee shops implement Wi-fi facilities as a service to attract customers. Noralona Coffee and Roastery is a coffee shop located in the city of Cirebon that provides Wi-fi facilities for its customers. Wi-fi facilities available at the coffee shop have not restricted user access to the internet. One of them uses a hotspot and the calculation of hotspot access is done using a voucher system. Hotspot with this voucher system will be configured with MikroTik. On the proxy there is a hotspot service feature, then there are additional features, namely User Manager, which is a web interface for hotspot management. Vouchers are calculated based on time. and each voucher can be used by 1 user. This study aims to produce hotspot vouchers that can be topped up through the hotspot login website to make it easier for consumers to use Wi-fi, do top ups and reduce the use of $\neg$ Wi-fi that is too long for each visitor. The results of this study indicate that in a time-limited and user-vouched test, users cannot log in if the voucher is being used by 1 user, and if the voucher deadline has expired, the voucher can be Top Up again and consumers can only Top Up Ix voucher in a day.
\end{abstract}

Keywords : Hotspot, Voucher, User Manager, Web Top Up, Top Up Voucher

\begin{abstract}
Abstrak
Kebutuhan akses internet saat ini sangat tinggi, baik itu untuk mencari informasi terbaru, artikel maupun mencari hiburan. Terdapat beberapa tempat yang menyadiakan untuk akses internet salah satunya adalah coffe shop. Banyak coffee shop mengimplementasikan fasilitas Wi-fi sebagai sebuah service untuk menarik pelanggan. Noralona Coffee and Roastery merupakan coffee shop berlokasi di kota Cirebon yang memberikan fasilitas $W i-f i$ untuk para pelanggannya. Fasilitas $W i-f i$ yang terdapat pada coffee shop ini belum membatasi akses user menggunakan internet. Salah satunya menggunakan hotspot dan perhitungan akses hotspot yang dilakukan dengan menggunakan sistem voucher. Hotspot dengan sistem voucher ini akan di konfigurasi dengan MikroTik. Pada MikroTik terdapat fitur layanan hotspot, kemudian terdapat fitur tambahan yaitu User Manager yang merupakan web interface untuk manajemen hotspot. Voucher dihitung berdasarkan waktu. dan setiap voucher dapat di gunakan oleh 1 user. Penelitian ini bertujuan untuk menghasilkan voucher hotspot yang dapat di top up melalui website login hotspot agar mempermudah konsumen dalam penggunaan $\mathrm{Wi}$ - $f$, melakukan top up dan mengurangi penggunaan $W i-f i$ yang terlalu lama untuk setiap pengunjung. Hasil dari penelitian ini menunjukan bahwa pada pengujian voucher berbatas waktu dan user, pengguna tidak dapat login apabila voucher tersebut sedang digunakan oleh 1 user, dan jika batas waktu voucher telah habis, voucher dapat di Top Up kembali dan konsumen hanya dapat melakukan Top Up voucher 1x dalam sehari.
\end{abstract}

Keywords: Hotspot, Voucher, User Manager, Web Top Up, Top Up Voucher 


\section{PENDAHULUAN}

Seiring dengan perkembangan zaman, kemajuan teknologi sudah semakin berkembang contohnya dalam penggunaan akses internet menggunakan Wi-fi. Penggunaan akses internet dengan $W i-f i$ sudah banyak kita temukan di berbagai tempat salah satunya yaitu di coffee shop karena kebutuhan akan akses internet menjadi salah satu daya tarik konsumen untuk datang maka diperlukan $\mathrm{Wi}-\mathrm{Fi}$ (hotspot) yang di jadikan sebagai titik akses internet. Hotspot adalah suatu bentuk pemanfaatan teknologi WLAN pada lokasilokasi publik. Hotspot sendiri merupakan suatu gambaran dari area atau lingkup tertentu yang terjangkau oleh frekuensi jaringan Wi-Fi sehingga pengguna dapat melakukan koneksi jaringan menggunakan perangkat yang memiliki teknologi $\mathrm{Wi}$-Fi seperti smartphone, laptop, dan sebagainya.

Cofee shop adalah sebuah tempat yang menjual dan menyediakan berbagai macam jenis kopi nusantara yang dapat diolah di tempat ataupun dapat dibawa pulang. Noralona Coffee Roastery yang berlokasi di kota Cirebon adalah salah satunya, coffee shop ini memberikan fasilitas hotspot untuk para konsumennya.

Pada penelitian yang berjudul "Implementasi Generate Voucher Hotspot Dengan Batasan Waktu (Time Based) Dan Kuota (Quota Based) Di Mikrotik" yang dilakukan oleh Tiara Sukma Fitria dan Agus Prihanto pada Universitas Negri Surabaya, Penelitian sebelumnya membahas tentang pengujian voucher time base atau voucher berbatas waktu diperoleh hasil bahwa user tidak dapat login kembali bila batas waktu voucher telah habis dan pada pengujian voucher quota base atau voucher berbatas kuota diperoleh hasil bahwa user tidak dapat login kembali bila kuota voucher telah habis , sistem voucher ini menjadi dasar agar dapat memudahkan pengguna dalam menggunakan hotspot , kemudian pengguna dapat menggunakan voucher yang berisikan id dan password sebagai akses untuk terkoneksi ke hotspot dengan cara login melalui web login [1].

Pada penelitian sebelumnya memiliki kekurangan yaitu pada web login yang hanya menampilkan form untuk login, web login tidak responsive ketika diakses melalui smartphone, untuk itu maka penyusun tertarik untuk mengembangkan penelitian sebelumnya, penyusun ingin menambahkan sistem web top up. Tор up merupakan aktivitas yang dilakukan oleh admin yaitu menambah saldo deposit milik member, proses top up saldo ini dilakukan pada sisi admin. Sehingga untuk melakukannya member harus mendatangi admin dan menyetorkan uang sebanyak yang telah ditentukan dan memberitahukan id member. Dengan menggunakan metode Radius, Radius merupakan suatu metode standar (protokol) yang mengatur komunikasi antara NAS (Network Access Server) dengan AAA (Authentication, Authorization, Accounting) server sudah dilengkapi fitur-fitur standar yang dibutuhkan. Dalam hal ini server AAA yang digunakan dapat juga disebut sebagai server RADIUS dan paket-paket data yang terlibat dalam komunikasi antara keduanya disebut sebagai paket RADIUS [2].

Sistem web top up ini akan dijadikan sebagai akses untuk melakukan pembelian voucher online, Pada web login akan ditambahkan form order voucher dan fitur top up atau pembelian voucher online. voucher online dapat dibeli dikasir atau setelah konsumen melakukan transaksi terlebih dahulu dan dapat top up melalui web login. Voucher yang sudah habis masa waktu akan di top up oleh admin sesuai paket yang di tentukan oleh konsumen melalui web base user manager, Untuk mengatasi permasalahan tersebut penyusun tertarik untuk melakukan pengembangan dengan menggunakan mikrotik RB952ui dan diterapkan sistem voucher sebagai akses login sebelum mengakses hotspot dan sitem top up sebagai akses untuk pembelian voucher online. Maka penyusun ingin mengambil judul Skripsi yaitu "Pengembangan Konfigurasi Hotspot dan Voucher Login Menggunakan MikroTik RB952ui dengan Sistem Web Top Up (Studi Kasus : Noralona Coffee and Roastery)".

\section{METODE PENELITIAN}

Prosedur penelitian atau metodologi penelitian yang dilakukan dalam penelitian ini menggunakan metode PPDIOO (Prepare, Plan, Design, Implementation, Operate, Optimize) network cycle [3].

Tahap prepare ini penulis melakukan observasi dan berkomunikasi dengan melakukan 
wawancara kepada owner coffee tentang proses bisnis dan kondisi jaringan yang sudah ada. Dalam tahap ini dilakukan pengumpulan data yang dilakukan dengan cara observasi. Pengumpulan data juga dilakukan dengan wawancara dan tanya jawab untuk memperoleh gambaran dan penjelasan mengenai kondisi jaringan internet yang ada di Noralona Coffee Roastery..

Tahap plan dilakukan pemetaan kebutuhan pelaksanaan pengembangan jaringan baru dan rencana anggaran yang dibutuhkan berbasis sistem voucher. Tahap design dimana penulis melakukan desain topologi jaringan dan menyiapkan rencana instalasi jaringan sesuai kebutuhan dan design website login. Tahap Implementation penulis melakukan pengecekan instalasi pengkabelan, memastikan seluruh proses sudah sesuai dengan desain dan melakukan konfigurasi sistem voucher dan pembuatan website login.

Tahap operate penulis melakukan kegiatan pengamatan pada jaringan komputer dan memastikan sistem voucher dan fitur top up dapat digunakan pada website login.

Tahap optimize adalah tahap akhir peneliti memprediksi dan meminimalisir masalah dan kegagalan yang akan terjadi

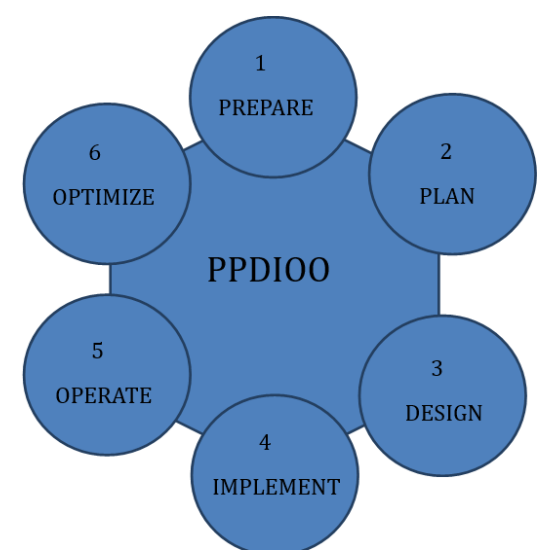

Gambar 1. Metode PPDIOO Network Cycle

\section{HASIL DAN PEMBAHASAN}

1. Prepare

Pada tahap ini penulis melakukan observasi dan berkomunikasi dengan melakukan wawancara kepada owner coffee tentang proses bisnis dan kondisi jaringan yang sudah ada. Dalam tahap ini dilakukan pengumpulan data yang dilakukan dengan cara observasi. Pengumpulan data juga dilakukan dengan wawancara dan tanya jawab untuk memperoleh gambaran dan penjelasan mengenai kondisi jaringan internet yang ada di Noralona Coffee Roastery. Berikut kondisi jaringan yang berjalan :

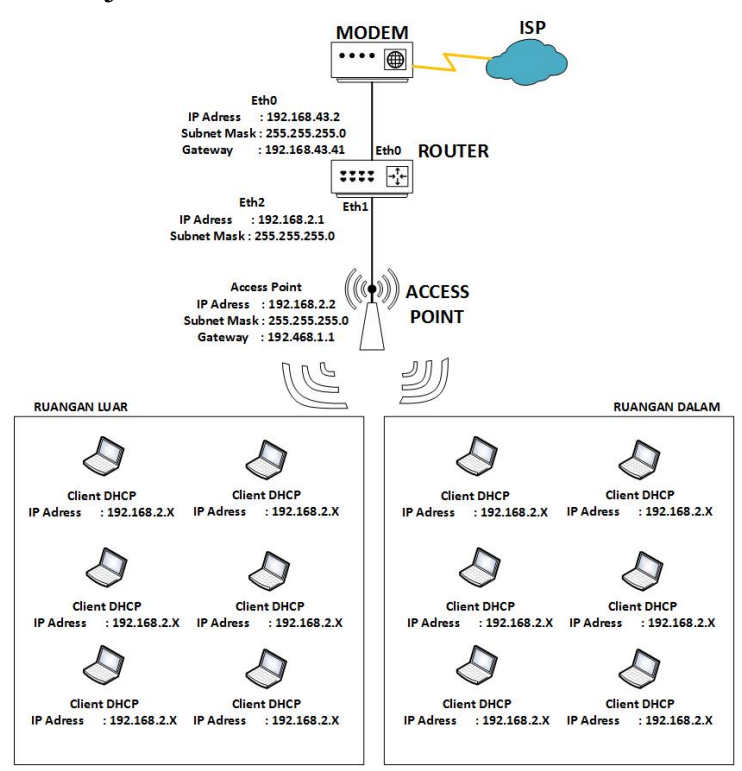

Gambar 2. Topologi Jaringan Berjalan

Topologi jaringan berjalan pada gambar 2 dimana router yang telah terhubung internet di hubungkan dengan access point yang telah di konfigurasi dan client terhubung dengan access point melalui jalur wireless dengan memasukan ID dan password

2. Plan

Tahap pemetaan kebutuhan pelaksanaan kebutuhan peralatan perangkat lunak dan perangkat keras dalam implementasi sistem voucher, berikut perangkat keras meliputi kabel UTP, Router Mikrotik RB952ui dan Access Point TL-WR840N

Tabel 1.1 Konfigurasi Router Mikrotik

\begin{tabular}{|c|l|l|l|}
\hline $\begin{array}{c}\text { Nama } \\
\text { Perangkat }\end{array}$ & \multicolumn{3}{|c|}{ Konfigurasi } \\
\hline & ip & add & $192.168 .43 .1 / 24$ \\
& $\begin{array}{l}\text { Addr } \\
\text { ess }\end{array}$ & $\begin{array}{l}\text { add } \\
\text { ress }\end{array}$ & \\
\cline { 2 - 4 } & ip & ip & $192.168 .43 .3-$ \\
Mikrotik & pool & ran & 192.168 .43 .254 \\
RB952ui & & ge & \\
\hline
\end{tabular}




\begin{tabular}{|c|c|c|c|}
\hline & $\begin{array}{l}\text { ip } \\
\text { dhcp } \\
\text { serve } \\
r\end{array}$ & $\begin{array}{l}\text { add } \\
\text { add } \\
\text { ress }\end{array}$ & $192.168 .43 .0 / 24$ \\
\hline & \multirow{2}{*}{$\begin{array}{l}\text { netw } \\
\text { ork }\end{array}$} & & \\
\hline & & $\begin{array}{l}\text { gat } \\
\text { ewa } \\
\text { y }\end{array}$ & 192.168 .43 .1 \\
\hline & \multirow[t]{2}{*}{$\begin{array}{l}\text { ip } \\
\text { hosto } \\
\text { p } \\
\text { profil } \\
\text { e }\end{array}$} & $\begin{array}{l}\text { hot } \\
\text { spo } \\
t \\
\text { add } \\
\text { ress }\end{array}$ & 192.168.3.1 \\
\hline & & $\begin{array}{l}\text { dns } \\
\text { na } \\
\text { me }\end{array}$ & Noralona.wifi \\
\hline & $\begin{array}{l}\text { radiu } \\
\mathrm{s}\end{array}$ & $\begin{array}{l}\text { add } \\
\text { ress }\end{array}$ & 192.168.43.1 \\
\hline \multirow[t]{10}{*}{$\begin{array}{l}\text { Web } \\
\text { Config } \\
\text { User } \\
\text { Manager }\end{array}$} & $\begin{array}{l}\text { User } \\
\text { mana } \\
\text { ger } \\
\text { route } \\
r\end{array}$ & $\begin{array}{l}\text { Ip } \\
\text { add } \\
\text { ress }\end{array}$ & 192.168.43.1 \\
\hline & $\begin{array}{l}\text { User } \\
\text { mana } \\
\text { ger } \\
\text { profil } \\
\text { e }\end{array}$ & $\begin{array}{l}\text { na } \\
\text { me }\end{array}$ & 1 jam \\
\hline & & $\begin{array}{l}\text { vali } \\
\text { dity }\end{array}$ & 1day \\
\hline & & $\begin{array}{l}\text { Peri } \\
\text { ode }\end{array}$ & $\begin{array}{l}\text { Monday,Tuesda } \\
\text { y, } \\
\text { Wednesday,thus } \\
\text { day, } \\
\text { Friday, } \\
\text { Saturday, } \\
\text { Sunday } \\
\end{array}$ \\
\hline & & $\begin{array}{l}\text { tim } \\
\mathrm{e}\end{array}$ & 01:00-00:00 \\
\hline & & $\begin{array}{l}\text { rate } \\
\text { limi } \\
\mathrm{t}\end{array}$ & $512 k$ \\
\hline & & $\begin{array}{l}\text { na } \\
\text { me }\end{array}$ & 2 jam \\
\hline & & $\begin{array}{l}\text { vali } \\
\text { dity }\end{array}$ & 1day \\
\hline & & $\begin{array}{l}\text { Peri } \\
\text { ode }\end{array}$ & $\begin{array}{l}\text { Monday,Tuesda } \\
\text { y, } \\
\text { Wednesday,thus } \\
\text { day, } \\
\text { Friday, } \\
\text { Saturday, } \\
\text { Sunday } \\
\end{array}$ \\
\hline & & $\begin{array}{l}\text { tim } \\
\mathrm{e}\end{array}$ & 01:00-00:00 \\
\hline
\end{tabular}

\begin{tabular}{|c|c|c|c|}
\hline & & $\begin{array}{l}\text { rate } \\
\text { limi } \\
t\end{array}$ & $512 \mathrm{k}$ \\
\hline & & $\begin{array}{l}\text { na } \\
\text { me }\end{array}$ & $1 \mathrm{~GB}$ \\
\hline & & $\begin{array}{l}\text { vali } \\
\text { dity }\end{array}$ & 1day \\
\hline & & $\begin{array}{l}\text { Peri } \\
\text { ode }\end{array}$ & $\begin{array}{l}\text { Monday,Tuesda } \\
\text { y, } \\
\text { Wednesday,thus } \\
\text { day, } \\
\text { Friday, } \\
\text { Saturday, } \\
\text { Sunday }\end{array}$ \\
\hline & & $\begin{array}{l}\text { tim } \\
\mathrm{e}\end{array}$ & 01:00-00:00 \\
\hline & & $\begin{array}{l}\text { rate } \\
\text { limi } \\
t\end{array}$ & $1 \mathrm{M}$ \\
\hline
\end{tabular}

Konfigurasi router Mikrotik pada tabel 2 memiliki beberapa tahapan dari menambah IP address hingga konfigurasi tipe pengguna. Dengan konfigurasi IP address 192.168.137.1/24, network 192.168.137.0 dan pool 192.168.137.3- 192.168.137.254. Pada hotspot konfigurasi DNS name menggunakan Noralona.wifi dengan address 192.168.2.1. konfiurasi radius dan usermanager router menggunakan ip server 192.168.137.1 karena database berada pada router tersebut.

Tabel 2 Pengaturan hak akses

\begin{tabular}{|l|l|l|}
\hline Profil & Hak Akses & \\
\hline \multirow{4}{*}{1 Jam } & Valid voucher & 1 day \\
\cline { 2 - 3 } & Periode & $\begin{array}{l}\text { Senin - } \\
\text { minggu }\end{array}$ \\
\cline { 2 - 3 } & Jam akses & $01: 00-00: 00$ \\
\cline { 2 - 3 } & kecepatan & $512 \mathrm{~K}$ \\
\hline \multirow{4}{*}{ jam } & Valid voucher & 1 day \\
\cline { 2 - 3 } & Periode & $\begin{array}{l}\text { Senin - } \\
\text { minggu }\end{array}$ \\
\cline { 2 - 3 } & Jam akses & $01: 00-00: 00$ \\
\cline { 2 - 3 } & kecepatan & $512 \mathrm{~K}$ \\
\hline \multirow{4}{*}{ GB } & Valid voucher & 1 day \\
\cline { 2 - 3 } & Periode & $\begin{array}{l}\text { Senin - } \\
\text { minggu }\end{array}$ \\
\cline { 2 - 3 } & Jam akses & $01: 00-00: 00$ \\
\cline { 2 - 3 } & kecepatan & $1 \mathrm{M}$ \\
\hline
\end{tabular}

Pengaturan hak akses pada tabel 2 memiliki 3 kategori yaitu 1 jam, 2 jam dan 
1 GB. Masing- masing kategori memiliki ketentuan berbeda disesuaikan dengan kebutuhan cafe.

3. Design

Tahap berikutnya yaitu design dimana penulis melakukan desain topologi jaringan dan menyiapkan rencana instalasi jaringan sesuai kebutuhan dan design website login

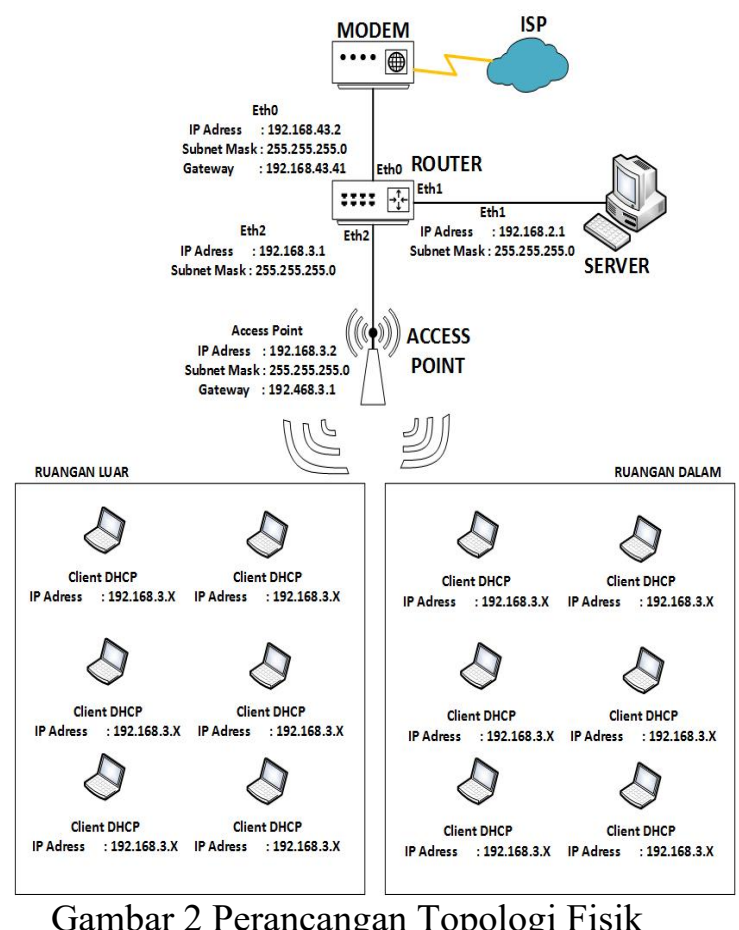

Perancangan topologi fisik pada gambar 2 memiliki router mikrotik yang sudah terkoneksi dengan internet melalui modem, kemudian server terhubung ke router mikrotik lalu router mikrotik dikonfigurasi oleh server melalui winbox dan router mikrotik yang telah dikonfigurasi dihubungkan ke access point lalu client terhubung dengan access point melalui jalur wireless menggunakan voucher yang di peroleh dan login kedalam website login voucher

4. Implementation

Berikutnya adalah tahap implementation penulis melakukan pengecekan instalasi pengkabelan, memastikan seluruh proses sudah sesuai dengan desain dan melakukan konfigurasi sistem voucher.

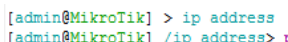

[admineMikroTik] /ip address> pt

Flags: X - disabled, I - invalid, D - dynamic

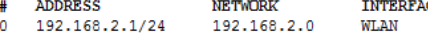

1 D $192.168 .137 .102 / 24 \quad 192.168 .137 .0$ modem

Gambar 3 Konfigurasi ip address mikrotik Konfigurasi IP address router Mikrotik pada gambar 5 memiliki IP address berbeda pada tiap network. Pada interface wlanWifi menggunakan network 192.168.2.0 dengan IP address 192.168.2.1/24. Konfigurasi router Mikrotik selanjutnya terdapat pada gambar 6
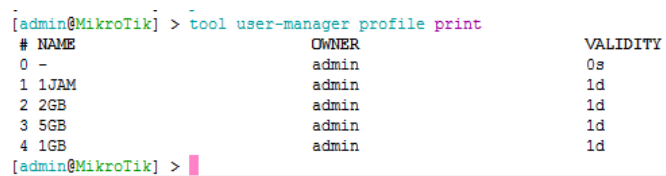

Gambar 4 Konfigurasi Profile

Pada konfigurasi profile router pada gambar 4 memiliki 4 kategori yaitu $1 \mathrm{jam}, 2 \mathrm{gb}, 5 \mathrm{gb}, 1 \mathrm{gb}$. Setiap kategori memiliki validitas waktu berbeda sesuai kebutuhan.

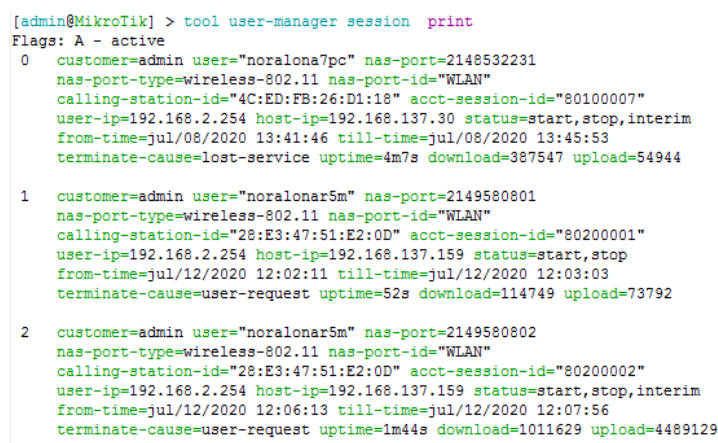

Gambar 5 Aktifitas Login Pengguna

Halaman aktifitas login pengguna dipantau oleh administrator melalui session.

5. Operate

melakukan kegiatan pengamatan pada jaringan komputer dan memastikan sistem voucher dan fitur top up dapat digunakan pada website login 

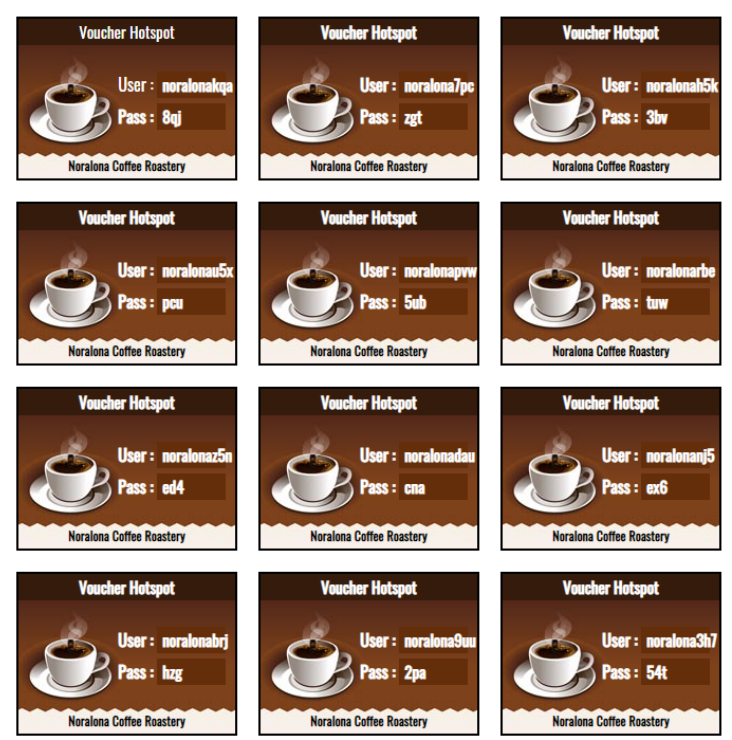

Gambar 6 Design Voucher

Tampilan voucher pada gambar 6 berisi informasi id dan password login hotspot Tampilan halaman login untuk memasukan voucher hotspot

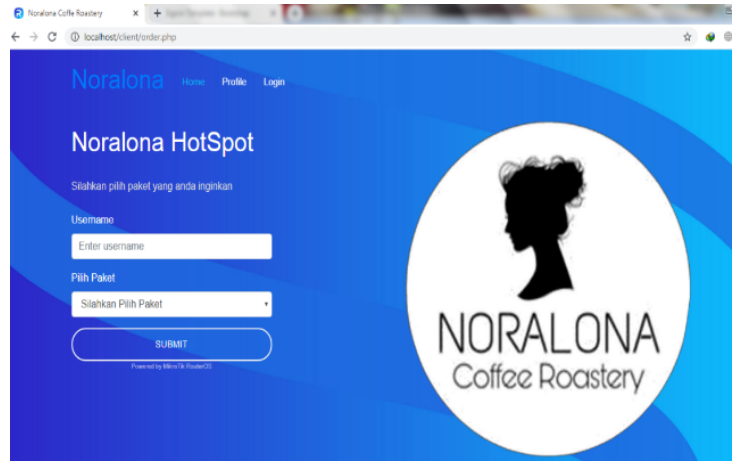

Gambar 7 Tampilan Halaman Login User

Halaman login hotspot Noralona Coffee Roastery pada gambar 7 berisi form login dan password untuk diisi oleh pengguna akses internet

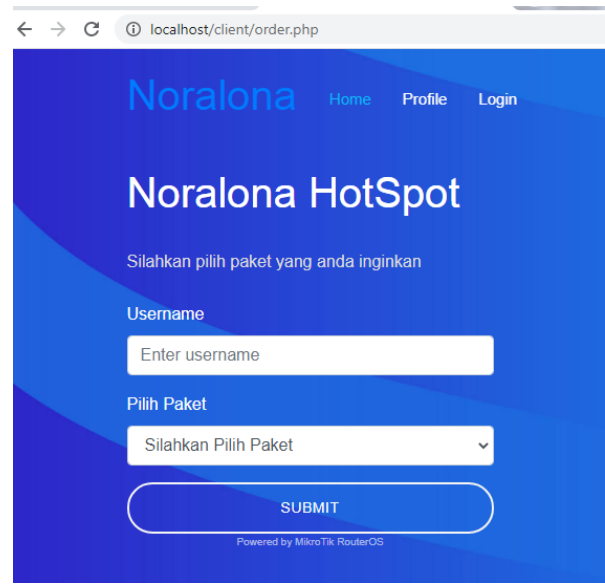

Gambar 8 Tampilan Order User
Halaman order vouicher pada hotspot Noralona Coffe Roaster pada gambar 8 berisi form order untuk diisi oleh pengguna akses internet untuk melakukan top up

6. Optimize

Tahap akhir adalah optimize peneliti memprediksi dan meminimalisir masalah dan kegagalan yang akan terjadi

\section{Interface <WLAN > Statistics}

- Last update: Mon Aug 3 22:38:21 2020

"Daily" Graph (5 Minute Average)

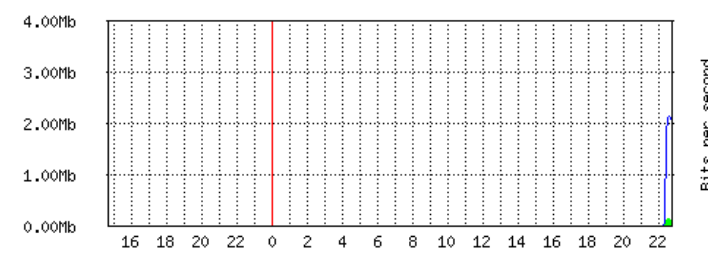

Max In: 108.53kb; Average In: 69.62kb; Current In: 100.60Kb; Max Out: 2.14Mb; Average Out: 1.36 Mb; Current Out: 2.09Mb;

Gambar 9 Grafik Aktifitas

Grafik akses internet sistem voucher terlihat waktu akses dan kecepatan akses pada sistem voucher router Mikrotik.

\section{SIMPULAN DAN SARAN}

Berdasrkan pembahasan dari penelitian ini dapat disimpulkan bahwa system voucher ini dibatasi oleh waktu dan voucher tersebut dapat di top up ketika masa waktu sudah habis.

Adapun saran dari pengembangan sistem ini kedepannya adalah metode untuk pembayaran diharapkan dapat dilakukan secara online dan menambah beragam paket internet.

\section{TERIMA KASIH}

Terimakasih untuk Bapak Rizal Rifai selaku owner Noralona Coffee Roastery yang telah membantu dalam penyusunan penelitian ini dan menyediakan data yang dibutuhkan.

\section{DAFTAR PUSTAKA}

[1] T. Fitria and A. Prihanto, "Implementasi Generate Voucher Hotspot Dengan Batasan Waktu (Time Based) Dan Kuota (Quota Based) Menggunakan User Manager Di Mikrotik," J. Manaj. Inform., vol. 8, no. 2, pp. 18-24, 2018.

[2] W. Frado Pattipeilohy, "Analisis dan 
Perancangan User Manager pada

Mikrotik Router dengan Sistem

Pembelian Kredit Voucher," J.

Sisfokom (Sistem Inf. dan Komputer), vol. 5, no. 1, p. 64, 2016, doi:

10.32736/sisfokom.v5i1.30.

[3] W. Adhiwibowo and W. Mindatama, "Implementasi Sistem Voucher dengab Router Mikrotik," Pengemb. Rekayasa dan Teknol., vol. 15, no. 2, pp. 118123, 2019. 